Cahiers $d u$ MONDE RUSSE

\section{Cahiers du monde russe}

Russie - Empire russe - Union soviétique et États indépendants

$52 / 4 \mid 2011$

Varia

\title{
Annick Morard, De l'émigré au déraciné
}

\section{Natalia Pashkeeva}

\section{OpenEdition \\ Journals}

Édition électronique

URL : http://journals.openedition.org/monderusse/7675

DOI : 10.4000/monderusse.7675

ISSN : $1777-5388$

Éditeur

Éditions de l'EHESS

\section{Édition imprimée}

Date de publication : 20 décembre 2011

Pagination : 835-839

ISBN : 978-2-7132-2353-2

ISSN : $1252-6576$

\section{Référence électronique}

Natalia Pashkeeva, «Annick Morard, De l'émigré au déraciné », Cahiers du monde russe [En ligne], 52/4 I 2011, mis en ligne le 03 décembre 2012, Consulté le 22 septembre 2020. URL : http://

journals.openedition.org/monderusse/7675; DOI : https://doi.org/10.4000/monderusse.7675

Ce document a été généré automatiquement le 22 septembre 2020.

(c) École des hautes études en sciences sociales 


\title{
Annick Morard, De l'émigré au déraciné
}

\author{
Natalia Pashkeeva
}

\section{RÉFÉRENCE}

Annick MORARD, De l'émigré au déraciné. La « jeune génération » des écrivains russes entre identité et esthétique (Paris, 1920-1940. Lausanne : L'Âge d'Homme (Slavica), 2010, $400 \mathrm{p}$.

1 Découvrir un surprenant univers " en vase clos » et délicatement pénétrer dans le milieu de l'émigration russe, familial mais fermé sur lui-même. C'est ce défi, non privé des charmes du secret et du mythe, qu'Annick Morard, une historienne suisse, s'est proposé de relever afin d'affiner notre connaissance de l'histoire culturelle de l'émigration russe dans l'entre-deux-guerres en France. L'intérêt de la démarche entreprise par A. Morard dans son ouvrage publié ${ }^{1}$ à partir de sa thèse de doctorat et récompensé par le prix Aksenenko en juin 2010, est considérable. Son étude apporte un nouveau souffle critique dans l'historiographie de l'émigration dont une partie très importante a été rédigée par les émigrés eux-mêmes qui ont été, certes, les acteurs de cette histoire, mais qui, par conséquent, restaient fortement impliqués dans le phénomène étudié, ce qui peut contrarier la distance critique que l'historien se doit d'avoir.

2 Il s'agit de peindre la vie des émigrés qui, en dépit de leur statut d'éléments étrangers dans une société qui les accueille, était riche de différentes manifestations intellectuelles et artistiques. Néanmoins, malgré cette abondance culturelle, ce sujet de recherche souffre encore d'un manque d'études universitaires conséquentes. S’il a fallu attendre la chute de l'URSS pour voir s'éveiller l'intérêt scientifique des chercheurs russes envers " la Russie en exil ", le thème reste peu exploré parmi les travaux universitaires des pays d'accueil. C'est pour ces raisons que les études de Catherine Gousseff, Gervaise Tassis, Leonid Livak, Oleg Budnickij, Ol'ga Demidova, Irina Kaspè 
sont importantes ${ }^{2}$. Ces travaux apportent de nouveaux éléments à la question de l'émigration simultanément à la destruction de ses mythes. Ainsi, ils démontrent la surévaluation traditionnelle du nombre de réfugiés depuis peu estimé à moins d'une centaine de milliers contre quatre cent mille individus auparavant. Ils démentent également l'isolement de la communauté russe réfugiée à Paris, mettant notamment en évidence les échanges culturels entre les intellectuels français et les Russes émigrés.

C'est dans cette trajectoire de démythification de l'émigration russe qu'Annick Morard positionne son ouvrage. Son objectif est de retracer le parcours de l'évolution intellectuelle et esthétique d'une génération des émigrés appelée " inaperçue » caractéristique enracinée dans l'historiographie après la parution en 1956 du célèbre ouvrage Nezamečennoe pokolenie de V. Varšavskij, lui-même membre de la génération en question. L'historienne se propose de faire une étude comparative du discours officiel de cette génération exprimée par la voie de la presse et de son discours littéraire révélé par ses œuvres, dans le but de distinguer ses intentions de ses réalisations, de présenter une image des valeurs qu'elle partageait afin de pouvoir, ensuite, distinguer la création individuelle des considérations générales.

4 La méthodologie de l'étude est bien fondée. En premier lieu, l'historienne spécifie le groupe intellectuel et artistique étudié que les représentants eux-mêmes, dans leur désir d'autodétermination, appellent la « jeune génération ». En se référant aux acteurs de l'émigration russe, dont notamment, V. Varšavskij, J. Terapiano, N. Berberova, G. Struve, à des historiens comme Irina Kaspè, et des sociologues comme Karl Mannheim, A. Morard déduit les critères possibles pour la définition du groupe étudié. La date de naissance, pour la plupart de ses représentants, est fixée entre 1900 et 1910 mais extensible à la fin du XIX ${ }^{e}$ siècle car, selon la juste remarque de Jean Cocteau, « une génération n'est pas faite de gens du même âge, ce sont des gens qui vivent ensemble » ${ }^{3}$. L'autre critère, subjectif mais significatif parce qu'il révèle une autodétermination des représentants du groupe étudié envers la Russie et les pays d'accueil, consiste à se considérer comme des " exilés » ayant gardés " peu de souvenirs de la Russie ». La sociologie propose, quant à elle, d'entendre sous le terme de " jeune génération » un groupe d'individus unis par une expérience commune, une même réflexion, un même mode de représentation du monde, un même système de pensée et de valeurs. Enfin, le conflit éternel des pères et des fils fait son apport dans la détermination du groupe étudié, en ce sens qu'une génération peut être aussi définie par opposition à celle qui la précède. Pour sa part, A. Morard précise la terminologie et propose d'introduire dans l'historiographie de l'émigration un autre terme, celui du " déraciné » qui décrit les jeunes, contrairement à l'« émigré » qui s'applique plutôt aux aînés.

5 L'étude de l'évolution historique et esthétique de la jeune génération se réalise à travers quatre phases. La première constitue la "préhistoire » de la question. Elle correspond à la période de 1918 à 1925 . À ce stade, l'analyse se base sur la revue Udar de Sergej Romov (1922-1923), les textes dadaïstes de Serge Charchoune (1921-1923), des poèmes de Valentin Parnah (1919-1922), les deux recueils de poésie de Mark Talov $(1920,1922)$, et quatre conférences faites par Il'ja Zdanevič (1921-1923). Le choix du corpus est représentatif. L'historienne atteint bien le but de traiter les auteurs et les textes peu analysés et qui représentent en même temps les divers courants littéraires.

6 La deuxième phase transitoire (1925-1930) de détermination des valeurs générationnelles communes est étudiée à partir des œuvres de Boris Božnev, Georgij Evangulov, Aleksandr Ginger et Dovid Knut. Le matériau est multiple: œuvres 
littéraires, conférences, articles de presse, souvenirs, recensions parus dans la presse russe et française. La période 1930-1934 est considérée comme la phase la plus importante. Durant cette époque, la jeune génération affirme son identité avec une esthétique qui lui est propre. La période correspond à la parution des deux revues : Les Nombres (Čisla), l'organe de presse de la jeune génération, et Cité Nouvelle (Novij Grad), l'organe de presse de l'ainée. Elles sont analysées dans le but de déduire l'esthétique dans sa manifestation officielle, donc exprimée par la voie de la presse. Lors de la quatrième et dernière phase (1934-1939), les valeurs générationnelles cèdent leur place à une manifestation apparente du personnel, à l'amplification du rôle du « Moi » dans les œuvres des jeunes. Ce dernier point sur l'évolution esthétique de la génération est étudié à travers des œuvres de Boris Poplavskij, Ekaterina Bakunina, Serge Charchoune et Gajto Gazdanov.

7 La manifestation intellectuelle et artistique des jeunes est toujours confrontée à la position des intellectuels français et émigrés de la génération des aînés. L'analyse démontre que la vie artistique des jeunes s'inscrit dans la vie agitée culturelle française de l'entre-deux-guerres. Ainsi, une base de données élaborée par Annick Morard repère les «occurrences françaises" dans la revue Les Nombres. Elle retient 112 entrées et affirme l'intérêt des jeunes Russes pour la littérature française. L'étude de la correspondance entre Charchoune et Tzara témoigne d'une forte volonté des jeunes de se faire entendre dans le milieu littéraire français. Cependant, Charchoune, se décrivant lui-même comme un dadaïste, reste peu apprécié et n'est pas intégré dans le milieu français. Ses œuvres témoignent de sa lutte permanente mais quelquefois vaine pour un droit à être entendu. Sa Foule immobile obtient une infime place dans la revue Le Coeur à barbe de Tzara qui, en une seule ligne, retient simplement l'apparition de l'œuvre sans le moindre jugement.

8 Les renvois aux critiques russes portant sur les œuvres des jeunes esquissent les rapports entre les deux générations d'émigrés. En se référant aux exemples cités dans l'ouvrage, on aurait même tendance à parler non de la jeune génération "inaperçue » mais bien souvent de la génération «incomprise». La critique de l'époque retient la solitude dont Poplavskij souffre durant toute sa vie, mais ne relève pas l'extrême importance que ce « solitaire de tendance dépressive » attribue à la question de l'amitié dans laquelle il voit un refuge possible. Le Corps de Bakunina attire l'attention des critiques par ces pages sombres que l'on considère comme décrivant les terribles conditions de vie de l'émigré-type. Son De l'Amour pour six est exclu de la littérature par Hippius qui estime que les caractéristiques du genre ne sont pas respectées et le classe plutôt dans la catégorie pornographique. A. Morard cherche un nouvel angle d'approche possible pour ces œuvres. Elle y voit la manifestation de l'individualité grâce à la réappropriation par l'individu de son propre corps, à travers le droit à l'hystérie, à la crise de nerfs qui se fondent dans une personnalité aux multiples « je ».

9 À ce double plan de confrontation des jeunes émigrés aux intellectuels français et russes abordé par l'historienne, on pourrait ajouter un troisième axe de comparaison. Il s'agirait de les confronter aux intellectuels de la Russie soviétique de l'époque, tels que E.I. Zamjatin, V.V. Majakovskij, les imaginistes, représentant les courants littéraires dont l'objectif était également de créer de nouvelles formes, visuelles ou verbales. Une telle étude aurait pu donner de nouveaux éléments importants, surtout si l'on considère le cas de certains jeunes écrivains russes qui ont quitté la France pour vivre l'expérience de la Russie soviétique (S. Romov, V. Parnah). 
10 Selon la juste remarque de Leonid Livak, les jeunes émigrés ont été enclins à profiter de la liberté créatrice sauvée du joug marxiste de leurs pays d'origine. Cependant, les rapports des jeunes Russes avec les intellectuels français et les émigrés mettent en évidence les conditions épineuses dans lesquelles leur puissance créatrice s'exprimait en France. La problématique de leurs œuvres le justifie intégralement. Ainsi, l'esthétisme des jeunes est plein de violence dans leur dénonciation de l'académisme, dans l'angoisse extrême de l'ultra-réalisme de certaines scènes décrites dans leurs œuvres (le couteau levé sur la victime) ou lorsqu'ils déforment la langue afin de rattacher leurs œuvres aux nouveaux mouvements littéraires. Les concepts fragiles de " sincérité » et d'« amitié » sont au premier plan de la révélation de la vie intérieure. C'est par cette trajectoire que les jeunes émigrés évoluent dans la vie culturelle en France dans l'entre-deux-guerres, dont l'évolution littéraire étudiée par Annick Morard illustre la transition progressive de la formation des valeurs communes à la manifestation d'un Je qui leur est propre.

\section{NOTES}

1. Avec le soutien de la Faculté des Lettres de l'Université de Genève et de la Fondation Erns \& Lucie Schmidheiny.

2. Catherine Gousseff, L'Exil russe : La fabrique du réfugié apatride, P. : CNRS, 2008 ; Gervaise Tassiss, L'œuvre romanesque de Mark Aldanov : révolution, histoire, hasard, Bern : P. Lang, 1995 ; Leonid Livak, How it was done in Paris: Russian émigré literature and French modernism, Madison : Un. of Wisconsin Press, 2003 ; Yu.A. Poljakov, O.V. Budnickij, eds, Periodičeskaja pečat' rossijskoj èmigracii, 1920-2000: sbornik statej, M., 2009 ; Olga Démidova, Metamorfozy v izgnanii: Literaturny byt russkogo zarubežjja, SPb., 2003 ; Irina Kaspè, Iskusstvo otsutstvovat': Nezamečennoe pokolenie russkoj literatury, M., 2005.

3. J.-M. Drot, Les Heures de Montparnasse : la voix des poètes, documentaire filmique, chapitre 3, Paris, INA prod., 1987. 